\title{
Bioinformatic analysis of multi-drug resistant class 1 integron- coded protein of Citrobacter freundii
}

\author{
Popoola, O. D., and *Thomas, B. T. \\ Department of Microbiology, Olabisi Onabanjo University, Ago Iwoye, Ogun State, Nigeria \\ *Correspondence to: benthoa2013@gmail.com; +2348064011412; ORCID: http://orcid.org/0000-0003-0675-5749
}

\begin{abstract}
:
Background: The understanding of the secondary structure of the class 1 integron coded protein is necessary to decipher potential drug target and also to infer evolutionary ancestry at the proteomic level. This study was therefore aimed at determining the secondary structure of class 1 integron-coded protein and also to provide information on their evolutionary ancestry.

Methodology: Five different sequences of Citrobacter freundii with the following accession numbers; KP902625.1, KP902624.1, KP902623.1, KP901093.1 and KP902609.1 were obtained using nucleotide BLAST (http://blast. ncbi.nlm.nih.gov/Blast.cgi) and subjected to evolutionary analysis, pairwise distance calculation, secondary structure and neutrality test using MEGA explorer, Kimura 2 parameter, SOPMA tool and Tajima's test respectively.

Results: Results of the NCBI queries revealed significant identity with class 1 integron of the studied Citrobacter freundii. The nucleotide sequence alignment depicted several conserved regions with varying degree of transitions, transversions, insertions, and deletions while the amino acid sequences of the nucleotides showed 42 conserved sites among all the sequences. The secondary structure of the class 1 integron coded protein depicted significant representation of the random coil $(43.74 \pm 3.24)$, alpha helix $(25.69 \pm 6.29)$ and the extended strands $(22.42 \pm 2.41)$ than the beta turns $(8.15 \pm 1.12)$. The Tajima's Neutrality test of five nucleotide sequences of Citrobacter freundii analyzed by considering the first, second and third codons as well as the non-coding regions revealed a total of 127 positions in the final datasets while the Tajima's Neutrality test was estimated to be $-0.1038$.

Conclusion: The study confirmed common evolutionary ancestor for the class 1 integron coded protein found in Citrobacter freundii. Our study also documents the higher representation of random coil, alpha helix and extended strands than the beta turns. The negative value of the Tajima's neutrality test suggests higher levels of both low and high frequency polymorphisms thus indicating a decrease in the class 1 integron population size and balancing selection
\end{abstract}

Keywords: Evolutionary, Protein structure, Class 1 integrons, Citrobacter freundii

Received Apr 11, 2019; Revised Aug 31, 2019; Accepted Sept 2, 2019

Copyright 2021 AJCEM Open Access. This article is licensed and distributed under the terms of the Creative Commons Attrition 4.0 International License $<$ a rel="license" href="http://creativecommons.org/licenses/by/4.0/", which permits unrestricted use, distribution and reproduction in any medium, provided credit is given to the original author(s) and the source. Editor-in-Chief: Prof. S. S. Taiwo

\section{Analyse bioinformatique de la protéine de Citrobacter freundii codée en intégron de classe 1 multi-résistante aux médicaments}

\author{
Popoola, O. D., et *Thomas, B. T.
}

Département de microbiologie, Université Olabisi Onabanjo, Ago Iwoye, État d'Ogun, Nigéria *Correspondance à: benthoa2013@gmail.com; +2348064011412; ORCID: http://orcid.org/0000-0003-0675-5749 


\section{Abstrait:}

Contexte: La compréhension de la structure secondaire de la protéine codée par intégron de classe 1 est nécessaire pour déchiffrer la cible potentielle du médicament et également pour déduire une ascendance évolutive au niveau protéomique. Cette étude visait donc à déterminer la structure secondaire de la protéine codée en intégron de classe 1 et aussi pour fournir des informations sur leur ascendance évolutionnaire.

Méthodologie: Cinq séquences différentes de Citrobacter freundii avec les numéros d'accession suivants; KP902625.1, KP902624.1, KP902623.1, KP901093.1 et KP902609.1 ont été obtenus à l'aide du nucléotide BLAST (http://blast. ncbi.nlm.nih.gov/Blast.cgi) et soumis à une analyse évolutive, en paire, calcul de la distance, test de la structure secondaire et de la neutralité avec MEGA explorer, le paramètre Kimura 2, l'outil SOPMA et le test de Tajima, respectivement

Résultats: Les résultats des requêtes NCBI ont révélé une identité significative avec l'intégon de classe 1 de Citrobacter freundii étudié. L'alignement de la séquence nucléotidique décrit plusieurs régions conservées avec un degré variable de transitions, transversions, insertions et délétions, tandis que les séquences d'acides aminés des nucléotides présentent 42 sites conservés parmi toutes les séquences. La structure secondaire de la protéine codée en intégron de classe 1 représentait une représentation significative de la bobine aléatoire $(43,74 \pm 3,24)$, de I'hélice alpha $(25,69 \pm 6,29)$ et des brins étendus $(22,42 \pm 2,41)$ par rapport aux tours bêta $(8,15 \pm 1,12)$. Le test de neutralité de Tajima de cinq séquences de nucléotides de Citrobacter freundii analysé en considérant les premier, deuxième et troisième codons ainsi que les régions non codantes a révélé un total de 127 positions dans les jeux de données finaux, tandis que le test de neutralité de Tajima était estimé à -0,1038.

Conclusion: L'étude a confirmé l'ancêtre commun de l'évolution pour la protéine codée en intégron de classe 1 trouvée dans Citrobacter freundii. Notre étude documente également la représentation plus élevée de la bobine aléatoire, de I'hélice alpha et des brins étendus que les tours bêta. La valeur négative du test de neutralité de Tajima suggère des taux plus élevés de polymorphismes à basse et à haute fréquence, indiquant ainsi une diminution de la taille de la population d'intégrons de classe 1 et de la sélection d'équilibrage.

Mots-clés: évolutionnaire, structure protéique, intégrons de classe 1, Citrobacter freundii

\section{Introduction:}

Integrons are genetic elements that contain the component of a site-specific recombination system which recognizes and captures mobile gene cassettes (1). These genetic elements have genes for an integrase (intI), a recombination site $(a t t I)$ and a promoter $\left(P_{C}\right)$ that allows the expression of the gene cassettes incorporated in the variable region (2) and also reshuffling of the gene cassettes and so they are called genetic construction kit for bacteria (3). These integrons usually harbor antibiotic resistant genes that play vital roles in the emergence of new multidrug resistant bacteria (4). This is because they equip bacteria with the ability to scavenge foreign genes, especially antibiotic resistance genes.

The subjection of antibiotic resistant gene cassettes to episodic selection leads to removal of unnecessary genes through excision events catalyzed by integrase which subsequently results in reduction of genetic burden (5). Integrons by themselves are not mobile $(6,7)$ but they may be part of mobile elements such as transposons and plasmids $(8,9)$ which further enhance the spread of antibiotic resistant genes. Antimicrobial resistance on its own, is a large and growing problem in infection control due to increase in the proportion of death as well as the cost of effective antimicrobial agents $(10,11)$.
Citrobacter freundii, which is the microorganism of interest in this study is an important food-borne and hospital-acquired pathogen, which causes diarrhea, urinary tract infection, peritonitis, bacteremia, brain abscess and meningitis (12-16). This organism is an opportunistic pathogen in aquaculture and has been reported to be associated with a wide spectrum of infectious diseases in aquaculture animals including gastroenteritis of one-year rainbow trout Oncorhynchus mykiss (17), red-leg syndrome of Rana catesbeiana (18), septicaemia of Garra rufa obtusa and Ziphius carvirostris (18, $19)$, systemic infection with no typical syndrome of Carcharhinus melanopterus (20), hepatopancreas necrosis and rotted gill of Cherax quadricarinatus, Portunus trituberculatus and Procambarus clarkii $(21,22)$.

In Gram-negative bacteria, different classes of integrons have been identified in several clinical isolates, where they contribute significantly to the prevalence and dissemination of antibiotic resistant genes $(23,24)$. This study therefore examined evolutionary relationship and the secondary structure of class 1 integron coded protein of Citrobacter freundii.

\section{Materials and method:}

The sequences KP902625.1, KP902624.1, KP902623.1, KP901093.1 and KP902609.1 were obtained using nucleotide BLAST (http://blast. ncbi.nlm.nih.gov/Blast.cgi) (25) and subjected 
to evolutionary analysis using the MEGA explorer (26). Pair-wise distances were calculated using Kimura 2 parameter. In MEGA explorer, translate option was used for converting the gene sequence into amino acid sequence. Sequence similarity search with BLASTP and best homologous protein was found using the multiple sequence alignment. The secondary structures of the protein sequences were predicted using SOPMA tool (27).

The analysis of the Tajima's test of Neutrality involved five nucleotide sequences. Codon positions included were the first, second, third and the non coding regions. All positions containing gaps and missing data were eliminated prior to the estimation of the Tajima's test.

\section{Results:}

The phylogenetic analysis of the class one integron coded protein of Citrobacter freundii retrieved from NCBI GenBank revealed significant evolutionary relationships. As shown in Fig 1, all the retrieved class 1 nucleotide sequences shared several conserved regions. In terms of relatedness of their class 1 integrons, organisms in cluster 1 (KP902625.1, KP902624.1, KP902623.1) are closer than those in cluster 2 (KP901093.1 and KP9026 09.1). Although, organisms in cluster 2 shared higher level of homology in their nucleotide sequence, the secondary structure of all the class 1 integron coded protein analyzed depicted significant representation of the random

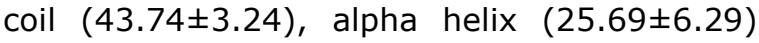
and the extended strands $(22.42 \pm 2.41)$ than the beta turns $(8.15 \pm 1.12)$.

Fig 2 represents the chromatograph of one of the Citrobacter freundii coded protein. The data in table 1 connotes the results from the Tajima's Neutrality test of five nucleotide sequences of Citrobacter freundii analyzed by considering the first, second and third codons and the non-coding regions. All positions containing gaps and missing data were eliminated. There were total of 127 positions in the final datasets while the Tajima's Neutrality test was calculated to be -0.1038 .

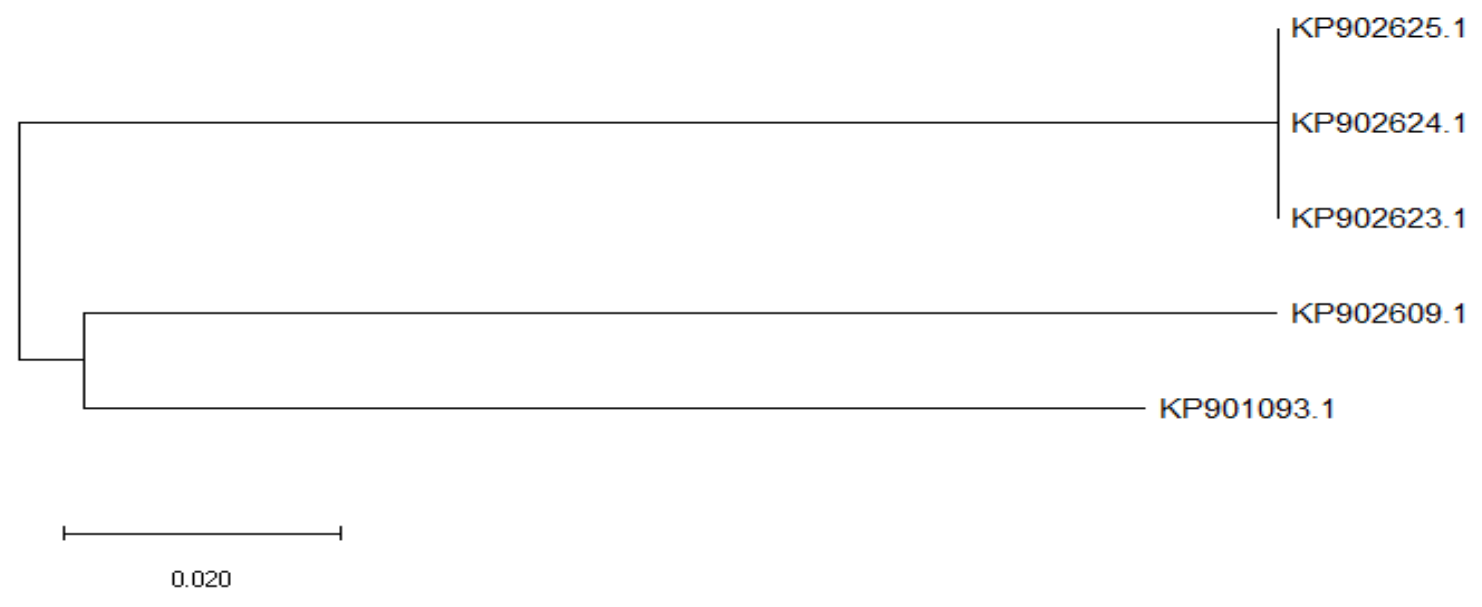

Fig 1: Phylogenetic relationship of class 1 integron-coded protein of Citrobacter freundii 

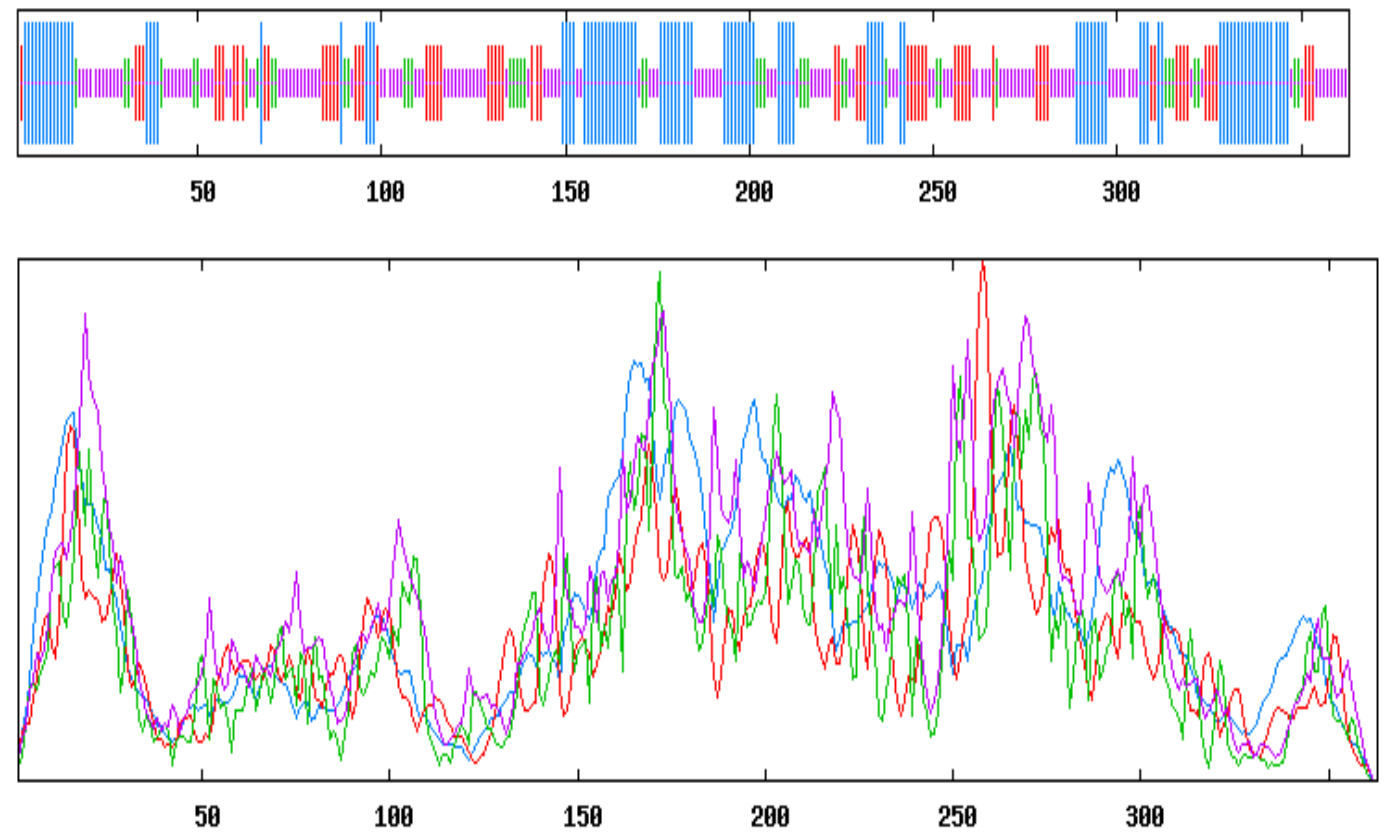

Parameters:

Window width:

Similarity threshold:

Number of states:

17
8

Fig. 2: Chromatographical representation of the secondary structure of JN108891

Table 1: Results of the Tajima's neutrality test

\begin{tabular}{cccccc}
\hline $\mathrm{m}$ & $\mathrm{s}$ & $\mathrm{ps}$ & $\theta$ & $\Pi$ & $\mathrm{D}$ \\
\hline 5 & 30 & 0.236 & 0.113386 & 0.11 & -0.1038 \\
\hline
\end{tabular}

$m=$ number of sequences, $n=$ total number of sites, $S=$ number of segregating sites, $P s=S / n, \theta=P s / a 1, \pi=$ nucleotide diversity, $D=$ Tajima's test of statistic

\section{Discussion:}

The use of protein structure and nucleotide sequences to understand evolution of cell and the function of genes cannot be overemphasized. According to Zuckerkandl and Pauling (28), evolutionary relationships between organisms can be studied by comparing their DNA sequences. In this study, a very high level of similarities was observed in the DNA sequences of the studied class 1 integron coded protein. This is an indication that class I integron may have common ancestors, with most of them probably being transferred as an insert in plasmid and/or transposons $(6,7)$.

The fact that some of the Citrobacter freundii connoted themselves together as a simplicifolious clade is an indication that the distribution of their nucleotide sequences is significantly related than those on other clades.
However, such observation may be connected to the fact that such acquired class I integron have been rearranged due to different levels of mutation resulting from substitution in form of transition, transversion, deletion and even insertions.

The BLAST analysis revealed homology with the available class 1 integrons of Citrobacter freundii present in the GenBank. The secondary structure analysis revealed comparatively higher random coil, alpha helix and extended strands than the beta turns. This knowledge is important as it helps in designing low-molecular-weight synthetic agents that reproduce their essential features (29) by using synthetic agents to mimic the helices. This in particular, has immense interest in drug dis- 
covery because of the central role the a-helical regions play in many biological processes.

\section{Conclusion:}

This study confirmed common evolutionary ancestor for the class 1 integron coded protein found in Citrobacter freundii. Our study also documents the higher representation of random coil, alpha helix and extended strands than the beta turns. Again, information about the amino acid residues in the class 1 integron coded protein is needed to study the binding of target drugs in these regions. This is because changes in these residues result in the modification of drug binding sites.

\section{Authors' contributions:}

ODP conceptualized the study and drafted the first manuscript. BTT carried out the bioinformatic analysis as well as data interpretation. All the authors approved the final version of the manuscript.

\section{Conflict of interest:}

Authors declared no conflict of interest.

\section{Funding:}

No funding was received for this study

\section{References:}

1. Hall, R. M. Mobile gene cassettes and integrons: moving antibiotic resistance genes in gram negative bacteria. Ciba Found Symp. 1997; 207: 192-202.

2. Hall, R. M., and Collis, C. M. Mobile gene cassettes and integrons: capture and spread of genes by site-specific recombination. Mol Microbiol. 1995; 15: 593-600.

3. Bennett, P. M. Integrons and gene cassettes: a genetic construction kit for bacteria. J Antimicrob Chemother. 1999; 43: 1-4.

4. Hall, R. M., Recchia, G. D., Collis, C. M., Brown, H. J., and Stokes, H. W. Gene cassettes and integrons: moving antibiotic resistance genes in Gram-negative bacteria. In: Ama'bile-Cuevas, C. F. (ed). Antibiotic Resistance: from Molecular Basics to Therapeutic Options. New York: Chapman and Hall. 1996: 19-34

5. Nield, B. S., Holmes, A. J., Gillings, M. R., Recchia G. D., Mabbutt, B. C., Nevalainen, K. M., and Stokes, H. W. Recovery of new integron classes from environmental DNA. FEMS Microbiol Lett. 2001; 195: 59-65.

6. Greenberg, B., Kowalski, J. A., and Klowden, M. J. Factors affecting the transmission of Salmonella by flies: natural resistance to colonization and bacterial interference. Infect Immun. 1970; 2 : 800-809.
7. Holt, P. S., Geden, C. J., Moore, R. W., and Gast, R. K. Isolation of Salmonella enterica serovar enteritidis from houseflies (Musca domestica) found in rooms containing Salmonella serovar enteritidis-challenged hens. Appl Environ Microbiol. 2007; 73: 6030-6035.

8. Wang, M., Sahm, D. F., Jacoby, G. A., Zhang, Y., and Hooper, D. C. Activities of newer quinolones against Escherichia coli and Klebsiella pneumoniae containing the plasmid mediated quinolone resistance determinant qnr. Antimicrob Agents Chemother. 2004; 48: 1400-1401

9. Musser, J. M. Antimicrobial agent resistance in mycobacteria: molecular genetic insights. Clin Microbiol Rev. 1995; 8 (4): 496-514

10. Pardia, S. N., Verma, I. C., Deb, M., and Bhujwala, R. A. An outbreak of diarrhea due to Citrobacter freundii in a neonatal special care nursery. Indian J Pediatr. 1980; 47 (1): 81-84.

11. Kim, B. N., Woo, J. H., and Ryu, J. Resistance to extended spectrum cephalosporins and mortality in patients with Citrobacter freundii bacteremia. Infection. 2003; 31 (4): 202-207.

12. Erkan, D., Zeki, Y., and Itir, Y. Citrobacter freundii peritonitis and tunnel infection in a patient on continuous ambulatory peritoneal dialysis. J Med Microbiol. 2007; 57 (1): 125-127.

13. Plakkal, N., Soraisham, A. S., and Amin, $H$. Citrobacter freundii brain abscess in a preterm infant: A case report and literature review. Pediatr Neonatol. 2013; 54 (2): 137-140.

14. Park, S., Song, S. H., and Lee, C. Bacterial pathogens in first febrile urinary tract infection affect breakthrough infections in infants with vesicoureteral reflux treated with prophylactic antibiotics. Urology. 2013; 81 (6): 1342-1345.

15. Svetlana, J., Dobrila, J., and Li, V. Citrobacter freundii as a cause of disease in fish. In Agris. 2003; 53 (5-6): 399.

16. Pasteris, S. E., Guidoli, M. G., and Otero, M. C. In vitro inhibition of Citrobacter freundii, a red-leg syndrome associated pathogen in raniculture, by indigenous Lactococcus lactis CRL 1584. Veter Microbiol. 2011; 151 (3): 336-344.

17. GunWook, B., JiHyung, K., and Choresca, J. C. Mass mortality of doctor fish (Garra rufa obtusa) caused by Citrobacter freundii infection. J Vet Clin. 2009; 26 (2): 150-154.

18. Fernandez, A., Vela, A. L., and Andrada, M. Citrobacter freundii septicemia in a stranded newborn Cuvier's beaked whale (Ziphius cavirostris). J Wildl Dis. $2011 ; 47$ (4): 1043-1046.

19. Lu, J., Sun, J., and Dong, S. Isolation and identification of pathogenic bacterium Citrobacter freundii from black reef shark Carcharhinus melanopterus. Trans Oceanol Limnol. 2015; 4: 8388.

20. Shen, J., Gu, Z., and Pan, X. Isolation and identification of Citrobacter freundii from Cherax quadricarinatus. J Fish Sci China. 2005; 12 (2): 197-200.

21. Yan, B., Zhang, X., and Liang, L. Detection of cfa gene and isolation and identification of the pathogen Citrobacter freundii isolated from Portunus trituberculatus. J Fish Sci China. 2012; 36 (3): 391-398.

22. Chen, H., Song, G., and He, J. Isolation, identification and antibiotics susceptibility test of Citrobacter freundii from Procambarus clarkii. Anim Husb Feed Sci. 2014; 6 (5): 238-241

23. Martinez, E., and De la Cruz, F. Genetic elements involved in $\operatorname{Tn} 21$ site-specific integration, a novel mechanism for the dissemination of antibiotic 
resistance genes. EMBO Journal. 1990; 9: 12751281.

24. Zuhlsdorf, M. T., and Wiedemann, B. Tn21-specific structures in Gram-negative bacteria from clinical isolates. Antimicrob Agents Chemother. 1992; 36: 1915-1921.

25. Altschul, S. F., Gish, W., and Miller, W. Basic local alignment search tool. J Mol Biol. 1990; 215: 403410

26. Tamura, K., Dudley, J., and Nei, M. MEGA 4: Molecular Evolutionary Genetics Analysis (MEGA) software version 4.0. Molecular Biology and Evolution. 2007; 24: 1596-1599
27. Geourjon, C., and Deleage, G. SOPMA: significant improvements in protein secondary structure prediction by consensus prediction from multiple alignments. Comput Appl Biosci. 1995; 11 (6): 681-684

28. Zuckerkandl, E., and Pauling, L. Molecules as documents of evolutionary history. J Theor Biol. 1965; 8 (2): 357-366.

29. Teo, J., Ngan, G., Balm, M., Jureen, R., Krishnan, P., and Lin. R. Molecular characterization of NDM-1 producing Enterobacteriaceae isolates in Singapore hospitals. Western Pac Surveill Response J. 2012; 3:19-24. 